\title{
Diversos Corpos Dançantes: Uma proposta de improvisação e dança na comunidade
}

\author{
Diversos Corpos Dançantes: A proposal
}

for improvisation and community dance

Carla Vendramin ${ }^{1}$

Lucas Reis Velho ${ }^{2}$

Wagner Ferraz ${ }^{3}$

\section{RESUMO}

Este artigo trata da criação de um espetáculo do projeto Diversos Corpos Dançantes, disparado pelo problema: Como criar estratégias pedagógicas e artísticas através da improvisação e composição coreográfica com diversos corpos? Destacam-se os processos das aulas, da criação e a apresentação artística, assim como a singularidade dos corpos e a coletividade do processo.

Palavras-chave: Dança na comunidade. Improvisação. Deficiência.

\section{ABSTRACT}

This article deals with the creation of a spectacle of Diversos Corpos Dançantes project, triggered by the problem: How to create educational and artistic strategies through improvisation and choreography with various bodies? We highlight the processes of classes, creation and artistic presentation, as well as the uniqueness of the bodies and the community in the process.

Keywords: Community dance. Improvisation. Disability. 
O presente artigo trata do processo de criação artística do grupo Diversos Corpos Dançantes (DCD), realizado em 2015. O grupo iniciou suas atividades em abril de 2014 como projeto de extensão, e está vinculado ao projeto de pesquisa $A$ Dança com Pessoas com Deficiência e Grupos de Habilidades Mistas, no Curso de Licenciatura em Dança da Universidade Federal do Rio Grande do Sul, coordenado pela Professora Carla Vendramin. Neste projeto trabalha-se com improvisação em dança e composição coreográfica, desenvolvendo uma poética da integração entre diversos corpos, seus movimentos e experiências. O projeto é identificado usando-se o nome grupo de habilidades mistas por possibilitar a participação de pessoas com e sem deficiência, de qualquer deficiência, e pessoas com ou sem experiência prévia em dança.

A nomeação de grupo de habilidades mistas se deu através do entendimento da deficiência a partir do modelo social (SWAIN, 2005), e entendendo que vivemos em uma sociedade em constante mudanças, as quais nosso vocabulário nem sempre dá conta de atender. Na sua trajetória, trabalhando com projetos de dança envolvendo pessoas com deficiência (VENDRAMIN, 2013), a coordenadora do grupo já utilizou várias nomeações: dança integrada (IDANÇA.NET, 2016), prática de dança acessível (INCLUSIVE.ORG.BR, 2016a), dança com pessoas com e sem deficiência (INCLUSIVE.ORG.BR, 2016b; G1.GLOBO.COM, 2016), oficina integrada de dança (SECRETARIA DA CULTURA DO RIO GRANDE DO SUL, 2016a), oficina de dança integrada/ inclusiva (CORPALAVRA, 2016) e, a partir de 2012 (SECRETARIA DA CULTURA DO RIO GRANDE DO SUL, 2016b), grupo de habilidades mistas. Essa nomenclatura passou a ser utilizada quando a citada coordenadora realizou uma residência artística em Milão, coreografando para a companhia Cie MixAbilities Dreamtime, de direção de Paola Banone ${ }^{4}$. No trabalho do DCD, nomear a dança envolvendo pessoas com deficiência não é uma condição fixa e sim processual, que ocorre de acordo com as necessidades que o trabalho informa, mas também contextualizando a sociedade em que vivemos. Assim como deficiência não é uma condição fixa, mas está em relação a construção social que se faz dela, nomear trabalhos que envolvem pessoas com deficiência acontece da mesma forma.

Ana Carolina Teixeira (2015), vem discutindo questões relacionadas a definição social da deficiência e o dançarino com deficiência em cena. A autora pesquisa a apropriação artística de dançarinos com deficiência e a condição de im/possibilidade, que é entendida com uma "revolução radical da deficiência como uma força criativa no seu próprio direito"5 (p. 10). Dessa forma ela também enfatiza que a condição da deficiência está relacionada aos modelos sociais e culturais, não sendo uma condição fixa.
4.

Paola Banone é diretora artística do Festival Internacional Dreamtime e da companhia com mesmo nome. Disponível em http:// www.festivaldreamtime.com/

5.

Tradução livre dos autores do original: radical revolving of disability as a creative force in its own right. 
Entendendo a transitoriedade do conceito de deficiência, e ampliando para o termo habilidades mistas, o grupo DCD anualmente recebe uma grande gama de participantes de diversas singularidades. Desses participantes, 19 dançarinos $^{6}$ entre 25 a 60 anos fizeram parte do processo artístico e das apresentações em 2015, incluindo a coordenadora e uma aluna bolsista. Os dançarinos que fazem parte do grupo Diversos Corpos Dançantes serão chamados neste artigo de dançantes (FERRAZ e BELLO, 2014). Para essa escrita, foram utilizados o registro em vídeo da apresentação ${ }^{7}$, anotações sobre o processo de criação e referências bibliográficas. As noções que irão operar conceitualmente no texto são específicas do campo da dança: habilidades mistas, dança na comunidade e improvisação. Estas serão articuladas com a escrita resultante do trabalho desenvolvido nas aulas e na cena, tendo em vista a singularidade e potência dos corpos.

Desde o início do grupo, já foram realizas uma série de apresentações na rua, em eventos variados e teatros da cidade de Porto Alegre/RS. Esse artigo irá discorrer apenas sobre o trabalho artístico do grupo realizado em 2015, que culminou com uma apresentação no Theatro São Pedro, no dia 08 de dezembro, um dos mais importantes espaços culturais do Estado e o teatro mais antigo da cidade. Primeiramente será abordada a noção de dança na comunidade e a constituição das aulas do grupo que adota a improvisação em dança como base do trabalho.

\section{A dança na comunidade}

No site Foundation for Community Dance, entidade com sede no Reino Unido, encontramos que a dança na comunidade se centra em três diretrizes: o contexto, a abordagem e os valores envolvidos. O contexto em que uma comunidade se encontra envolve: onde, com quem e porquê determinado trabalho é realizado. A abordagem da prática de dança é informada pelo conjunto de crenças e filosofias relacionadas a uma determinada comunidade. Da mesma forma, se leva em consideração os valores pertencentes a essa comunidade e como ela os promove. Dança na comunidade envolve todas as pessoas e qualquer pessoa. Ela é uma arte de participação, pois cria oportunidades para que um número diverso de pessoas acesse com qualidade a experiência da dança, independentemente de onde elas vivem, sua idade, gênero, sexualidade, raça, deficiência, realização educacional ou circunstâncias econômicas.

Nesse tipo de proposta, os participantes não precisam ter aspirações de desenvolverem um trabalho profissional em dança, porém, ele é um caminho enriquecedor que também dá possi-
6.

Adrolilda da Conceição,

André Olmos, Carla Vendramin,

Cleonice Conceição Ferreira, Ferhi Mahmood, Gessi Lopes, Gustavo L. Pires, Guaraci O. Da Silva, Julia Favero, Katie Niedermeir, Leila Mylius, Maíra Oliveira, Maria Helena Magnus, Marta Schneider, Miriam Niedermeir, Rogério Per França, Rosane Favero, Rosaura Severo e Tatiana M. Lima.

7 .

Vídeo disponível no link https://www.youtube.com/ watch?v=zfvgFdTpQb8\&

feature=youtu.be

Outros links do grupo: http://diversoscorposdanc. wixsite.com/diversos-corpos e https://www.facebook.com/ diversoscorposdancantes/

8. Disponível em: http:// www.communitydance.org.uk/ membership-services/ professional-code-of-conduct Acesso em 4 de Setembro de 2016. 
bilidades de se progredir para uma profissionalização. Apesar disso, os artistas facilitadores dos projetos da dança na comunidade devem ser aptos a criar trabalhos de qualidade artística. Esses profissionais especializados se denominam artistas, praticantes, facilitadores ou líderes da dança na comunidade. Outros profissionais apenas se denominam artistas da dança, sem levar a referência a palavra comunidade. No Reino Unido, alguns desses artistas trabalham em tempo integral em ambientes comunitários e outros combinam seu trabalho da dança na comunidade com outras atividades profissionais, atuando como dançarinos e coreógrafos, e em outros contextos como professores, como exemplo, Rosemary Lee em Square Dances (2011) e Common Dance (2009). Algumas companhias são especializadas no trabalho da dança na comunidade, como Entelechy Participatory Arts Company e Green Candle Dance Company. O Foundation for Community Dance é referência para a congruência, informação e difusão do trabalho de dança com pessoas com deficiência, o qual se insere na proposta de dança na comunidade.

A dança na comunidade pode acontecer em qualquer lugar e em todo lugar. Ela se encontra em variados contextos que possuem uma gama de condições específicas que, geralmente, acontecem fora da escolaridade obrigatória e das configurações de treinamento, ou contextos de desempenho profissional. As atividades podem ser autofinanciadas, com subsídio na forma de doações de organizações de financiamento ou patrocinadas através de incentivo governamental e empresas apoiadoras. A dança na comunidade não se limita a um tipo específico de dança. Ela está centrada em envolver as pessoas de modo criativo e com segurança, explorando ideias da dança e encontrando formas próprias, dentro ou fora de um gênero específico de dança. Ela pode envolver a criação e apresentação de performances onde a experiência e o processo de fazer dança sejam o mais importante, e não o alcance do produto. Por isso ela acontece de muitas formas em que se pode propiciar participação, aprendizado, criação de performance e também praticar, observar e falar de dança. O movimento da dança na comunidade no Reino Unido tem o objetivo de contribuir para o desenvolvimento da dança como uma forma de arte, e apoiar o desenvolvimento artístico de dançarinos profissionais e não profissionais. Ela se propõe a trazer um impacto positivo à motivação pessoal e aos relacionamentos sociais das pessoas, assim como contribuir com o bem-estar e a saúde. A dança na comunidade oferece novas maneiras de se relacionar com outras pessoas, com base no respeito e na valorização da diferença. Ela tem o objetivo de melhorar a qualidade das relações entre as pessoas, suas comunidades e a qualidade artística de suas danças, trazendo uma contribuição positiva para uma 
mudança social mais ampla e para o fomento de programas artísticos e de aprendizagem da dança.

O termo dança na comunidade ou dança para comunidade, ganhou visibilidade graças ao Foundation for Community Dance, que definiu o conceito, explicitou os seus objetivos, qualidades e características, identificando essas práticas. Varregoso (2014) destaca que a dança na comunidade são ações que são dirigidas a todos, implicando a atuação de artistas que trabalham com pessoas comuns. Este conceito também é reforçado por Amans que aponta que:

\begin{abstract}
A Dança na Comunidade é sobre dança não elitista [...] pode ser sobre a criação de obras que quebram estereótipos sobre o que a dança é, e o que são os dançarinos, pode ser sobre performance em lugares não tradicionais. Ela pode ser qualquer coisa que nós, a Comunidade, queiramos que seja. (2008, apud VARREGOSO et al. 2014, p. 5).
\end{abstract}

Kuppers (2007) traz o conceito de performance na comunidade e sua ampla possibilidade de definição, a partir do entendimento de um trabalho que facilita a expressão criativa de grupos diversos de pessoas, e tem o objetivo de propiciar a expressão pessoal e gerar mudanças políticas. Para ela o conceito de comunidade depende do entendimento das tensões existentes entre pessoas como indivíduos, e pessoas como membros de um grupo. Envolve as dinâmicas de inclusão e exclusão que emergem em uma comunidade, e as múltiplas definições sobre comunidade existentes de acordo com a análise de como surgem, atuam e são reguladas por elas mesmas. Na sua definição, performance comunitária está centrada no ato de trabalhar junto, permitindo emergir diferentes vozes, corpos e experiências. A performance comunitária é criada colaborativamente e se pauta no processo ao invés do produto, permitindo transformações tanto dos indivíduos como da estrutura social. Baseia-se em como a diferença e a pluralidade podem ser uma força motriz para a performance na comunidade.

O grupo Diversos Corpos Dançantes se identifica dentro da perspectiva de atuação da dança na comunidade. De acordo com a ampla possibilidade de trabalhar com uma comunidade de diversos corpos, a improvisação é um recurso importante que proporciona o acesso a dança. A seguir será explanado sobre a constituição das aulas do grupo através da improvisação em dança.

Improvisação para a constituição das aulas

A improvisação é um recurso que concebe a base do trabalho do DCD. A partir dela a dança a as composições acontecem se 
desenrolando através de três focos: (a) atenção sobre o corpo; (b) relação com o outro; (c) atenção sobre o espaço, as relações "entre"9 (conexões e dinâmicas que acontecem entre grupo/ corpo/espaço). A inter-relação com o ambiente e entre corpos, a mudança dos focos interno e externo através da atenção à percepção, leva a investigação da sinergia entre os participantes, propiciando que encontrem novas relações sobre o corpo e descobrindo movimento juntos, criando um processo artístico singular ao grupo. A pergunta - que conhecimento construímos juntos? - permeia a prática, enquanto se constrói através dela, meios de verbalizar e dar visibilidade ao processo vivenciado, pesquisando a especificidade e o funcionamento das singularidades e da coletividade desses diversos corpos dançantes. O trabalho a partir dos três focos permite que os participantes potencializem individualmente o conhecimento sobre seu próprio corpo, que observem e compreendam as relações com tempo e espaço, bem como as relações interpessoais para a criação da improvisação em dança, e que se apropriem criativamente do seu desenvolvimento pessoal e em grupo.

As aulas iniciam e terminam com a piscina, momento em que o grupo se coloca em círculo e conversa sobre o processo vivenciado no dia ou sobre qualquer questão que possa surgir. A piscina foi proposta por Luciana Hoppe ${ }^{10}$ em 2014, quando ela participava do grupo e atuava nele como professora. Desde então o grupo adotou a piscina como um momento inicial e final da aula, onde se tem espaço para o compartilhamento. Além de possibilitar a participação dançando, o projeto vem sendo um meio de dar experiência docente e colaborar com a formação de professores de dança. O projeto conta com alunos do Curso de Licenciatura em Dança da UFRGS que também atuam como professores, além de praticantes e professores de dança de fora dessa instituição, onde todos compõe um núcleo de pesquisa em docência dedicado as experiências desenvolvidas.

O momento inicial da aula convida a aquecer os sentidos e, assim, não apenas preparar o corpo para se mover, mas também estar atento a sensação cinestésica, a localização e relação do seu corpo com o espaço da sala, a observação através do olhar, a sensação tátil e de pressões sobre o corpo, etc. Após essa introdução, são feitas propostas de facilitação da improvisação, a partir de conteúdos variados. Esses conteúdos podem se constituir com perguntas, tarefas ou imagens, por exemplo, a partir dos padrões filogenéticos do Body Mind Centering ${ }^{\circledR}$ como vibração, pulsação, etc (COHEN, 2012). Existe uma infinidade de possibilidades provindas dos conteúdos da dança, as quais, algumas foram elegidas no decorrer do histórico de desenvolvimento do grupo. A conexão e interação entre os participantes são proporcionadas com atividades de improvisação como: a) guia-seguidor;
9.

Ferraz (2014) trata do "entre" como um infinito de possibilidades, aquilo que dá condições para as relações e para a constituição dos corpos.

10.

Licenciada em Dança pela Universidade Estadual do Rio Grande do Sul - UERGS. Mestranda no Programa de Pós Graduação em Artes da Cena do Instituto de Artes da UNICAMP. 
b) oposição-imitação; c) trajetórias espaciais; d) tocar e mover; e) mover através do som; f) mover através do toque; entre outras que surgem de acordo com o andamento das aulas ${ }^{11}$.

As proposições são feitas de modo que os participantes entrem em contato com as possibilidades singulares do seu corpo e conheçam o corpo do outro, sempre ampliando para o espaço e a observação das relações envolvidas. Isso pode ser observado em atividades com trajetórias espaciais, cuja proposição de movimento seja variação de velocidades. Nessas atividades, os participantes são estimulados a observar a sua ação individual e como seu corpo afeta o corpo do outro. Eles também são estimulados a perceber como acontecem as dinâmicas de movimento e relacionamento entre eles, que são construídos coletivamente na sua relação de tempo. Os participantes são lembrados de usar por vezes mais o foco interno (das sensações internas do seu corpo) ou mais o foco externo (o olhar para o espaço, a interação com o outro e a observação das dinâmicas que o grupo constrói juntos). Dançar também é observar. Por vezes se destaca a importância de observar as relações de movimento que criam enquanto dançam. Após experimentarem uma proposição, são divididos em pequenos grupos, duos ou trios que apresentam suas investigações dançantes.

O grupo é estimulado a estar atento as relações de movimento presentes e comentá-las para que, assim, se traga visibilidade, entendimento e apropriação da criação em dança vivenciada. Entre muitas variantes, são observadas as escolhas feitas com relação ao posicionamento e deslocamento no espaço, as qualidades de movimento envolvidas, o estado de presença, a escuta do tempo e da relação com o outro. Além desse momento de trabalho em grupo, existem outros no decorrer da aula em que se observam especificidades que são colocadas em discussão. Em uma das aulas, por meio de uma proposta de improvisação de contato trazida por André Olmos, a participante Gessi Lopes, que possui hemiplegia, descobriu junto com ele, como sair e voltar do chão. Esse conhecimento então foi compartilhado e disseminado no grupo, fazendo parte do escopo de entendimento de possibilidades do movimento e suas relações, não só para a participante com hemiplegia, mas para todo o grupo. Em outro dia, a dúvida era sobre o quanto do peso do próprio corpo pode-se colocar sobre uma pessoa na cadeira de rodas. Também, em que lugares diferentes de uma cadeira de rodas se pode colocar o peso. Se conversou sobre porque isso funciona de forma distinta para diferentes cadeirantes. Na prática do grupo emergem assuntos sobre a corporeidade dos indivíduos e a sinergia da dança que estamos construindo juntos.

As atividades nas aulas se desenvolvem inicialmente com uma tarefa bastante simples, onde os elementos vão sendo
11.

Não serão examinados em detalhe todos os conteúdos da dança que envolve as atividades do grupo, pois isso demandaria uma escrita extensa. 
colocados em camadas, construindo uma complexidade maior no seu decorrer. A coordenadora do grupo chama esse modo de trabalho de princípio progressivo ou construção da informação em camadas. Isso é, a complexidade vai aumentando gradativamente e as propostas são adicionadas uma envolvendo a outra de forma a se complementarem. Durante o percurso, quem está facilitando a improvisação observa como está se dando a dinâmica do grupo e faz alterações conforme necessário. Essa forma de trabalhar propicia que pessoas que tenham dificuldades cognitivas mergulhem no processo através da sinergia da sua corporalidade e da sinergia da relação com o grupo, pois as tarefas não são somente entendidas a partir de uma explicação verbal, mas através de vivenciar e aumentar a complexidade durante o fazer, isso é, em feedback circular com a prática. Igualmente, isso possibilita que pessoas sem muita experiência em dança ou que não estão familiarizadas com a percepção do seu próprio corpo, encontrem um modo fácil e orgânico de entrar no processo. Além disso, os bailarinos com mais experiência encontram um meio de também desenvolverem sua habilidade para intensificar a escuta sobre as possibilidades do seu movimento e a sua influência cinestésica.

O grupo é uma entidade viva. A facilitação da improvisação precisa aguçar a percepção e a criatividade. Quando aparece algo no processo que parece dar errado, geralmente é porque falta alguma informação ou orientação, ou afinamento de comunicação, ou existe alguma inadequação da proposta oferecida para aquele grupo especifico. Quando isso acontece, a partir do problema apresentado, se encontra alguma solução que é compartilhada pelo grupo inteiro. A proposta de improvisação pode então ser mudada ou reformulada de outra maneira, reduzida ou ampliada de modo que se restabeleça um entendimento coletivo sobre o que se está fazendo. Às vezes isso acontece a partir da singularidade de um dos integrantes, como no caso de um participante que sem muita mobilidade corporal começou a utilizar sons como motes de dança, e para indicar possibilidades para os colegas se moverem. A partir disso, se começou a criar improvisação e coreografia cujo mote de movimento se deu por meio do som. Na apresentação realizada no Theatro São Pedro, isso pode ser visto no momento do duo Carla-Gusta e nos três duos no chão ${ }^{12}$. Assim, o repertório das aulas se constitui por propostas de improvisação previamente elaboradas e outras que surgem a partir da singularidade de algum integrante ou de alguma dinâmica encontrada a partir do grupo.

A música é utilizada como mais um elemento, tomando o cuidado para que ela não prepondere em relação a todas as outras informações necessárias para dançar. No processo de criação artística para as apresentações do grupo, o uso da música como
12.

Gustavo Pires, dançante cadeirante do Diversos Corpos Dançantes. Duo disponível em https://www.youtube.com/ watch?v=zfvgFdTpQb8\& feature=youtu.be (14 $\mathrm{min}$.) Acesso em 30 out. 2016 
referência não autoritária e determinante do movimento é fundamental. No momento final da aula, o grupo faz um círculo, os participantes posicionam as palmas da mão no encontro com a palma da mão do outro, ou outra parte do corpo, para fazer uma pressão para fora e criar uma vibração crescente, se impulsionando e fazendo uma explosão para fora, que é acompanhada com som e um grito coletivamente construído. Assim, a celebração é parte constitutiva da forma de terminar uma aula.

\section{Singularidades e coletividade em cena}

Além dos dançantes integrantes do grupo DCD, participaram da apresentação no Theatro São Pedro, os seis integrantes da banda Novo Circo Companhia de Dança. A banda era composta por músicos que atuam nas artes cênicas ${ }^{13}$. Também participaram dessa apresentação oito artistas convidados, sendo seis de Porto Alegre $(R S)^{14}$, uma de Caxias do $\operatorname{Sul}(\mathrm{RS})^{15}$ e uma vinda da cidade de Porto em Portugal ${ }^{16}$. O espetáculo exibiu peças da coleção da obra Estranhos Vestíveis da artista visual Lisi Rabello e contou com uma equipe de apoio formada por monitores, professores, técnicos e produtores ${ }^{17}$.

O processo de criação artística se desenvolveu no período entre maio e dezembro de 2015. O grupo fez uma primeira apresentação no teatro do Centro Cultural Santa Casa, em 22 de setembro, a convite do programa Integre-se $e^{18}$ da Santa Casa de Misericórdia de Porto Alegre. Os dançarinos convidados não participaram dessa apresentação. Na ocasião houveram duas apresentações gratuitas, sendo uma para o quadro de funcionários da instituição e outra aberta ao público em geral. A apresentação no teatro da Santa Casa trouxe as principais improvisações e coreografias apresentadas posteriormente em dezembro. O grupo DCD e a Banda Novo Circo Cia de Dança se encontraram pela primeira vez nesse dia, diretamente no palco no momento da apresentação. Isso foi somente possível devido ao modo de trabalho adotado com relação a escuta do corpo e não dependência da música. Também, devido ao fato de que a banda era formada por artistas circenses e dançarinos, com muita experiência em improvisação na atuação como artistas cênicos, tanto quanto como músicos que criam sonoridades para artistas da cena.

Os dançantes do DCD foram preparados para entender que o movimento se desenvolve a partir das relações corpo-outro-espaço e não prioritariamente a partir de uma música. Isto significa que independente da música a ser utilizada ou mesmo não fazendo uso da música, o dançante é capaz de compor a sua movimentação. Por causa disso o encontro da improvisação musical trazida pela banda e a dança do grupo foi bastante fluido. A maioria das
13.

A banda Novo Circo Companhia de Dança é formada por Gabriel Grillo (Guitarra e Cristal), Guilherme Guinalli (Teclados e Claves), Gustavo Tomé, Margarina Bailarina ( Malabares e instrumentos de sopro), Mauro Pogorelsky (Baixo e diabolo), Paula Finn (Ukulele, castanholas e percussão. Dança) e Paulo Zé Barcellos (Bateria e Clown).

14.

Ana Medeiros, Daniela Cezar, Marco Fillipin, Robson Duarte, Thais Petzhold e Vera Carvalho. 15.

Roberta Spader, é muletante e usa a cadeira de rodas como mais uma possibilidade criativa para a dança.

16.

Mickella Dantas, dançarina capixaba com trajetória nos grupos Roda Viva, Candoco e Dançando com a Diferença. Atualmente mora em Portugal onde também trabalha como dançarina em grupos não inclusivos.

17.

Produção: Íris Produções - Plínio Marcos e Viviane Falkenback. Monitores bolsistas (Prorext): Maíra de Oliveira e Marco Chagas. Monitor voluntário: Lucas Reis. Professores: André Olmos, Daniel Eliseu de Souza, Guaraci da Silva (Broder), Luciana Hoppe, Maíra de Oliveira e Marco Chagas. Iluminação: Bathista Freire e Kyrie Isnardi. Figurino: Vanessa Berg Estúdio Hybrido. Divulgação: Eduardo Severino. Fotografias: Jorge Diehl. Produção de vídeo: Maurício Pflug.

18.

Programa institucional da Santa Casa que busca promover a inclusão de pessoas com deficiência no ramo hospitalar, contribuindo para o desenvolvimento profissional e institucional. Disponível em: https:// www.santacasa.org.br/pt/trabalhe-conosco/programa-integre Acesso em o7 de Abril de 2016. 
músicas eram improvisações criadas em cima de atmosferas pré-definidas, com exceção de $O$ Vento que Leva e Coelhinho. Tanto o DCD quanto a Banda Novo Circo tinham a improvisação imbricada no seu processo artístico, por isso também esse primeiro encontro aconteceu de forma fácil e espontânea.

A coordenadora do grupo visitou vários ensaios da banda onde se conversou sobre cada uma das cenas. A banda criou atmosferas musicais específicas a cada uma delas e conheceu os momentos de entrada e saída das cenas. Porém a improvisação, a escuta de estar presente em cena e nas suas relações, fizeram com que esse encontro da dança e da música acontecesse sem nenhum ensaio prévio da banda com o grupo antes da primeira apresentação. Os ensaios do grupo eram realizados com músicas provisórias variadas e também sem música. A música era entendida como mais um elemento para se relacionar, mas não o mais prioritário ou o único. Dessa forma, quando o grupo encontrou a banda, eles estavam preparados para dançar qualquer música que eles tocassem. Porém, mais importante que isso, estavam sensibilizados a se relacionarem com a banda e a proposta musical que traziam. Nessa primeira apresentação, apenas uma música, intitulada Coelhinh ${ }^{19}$, foi coreografada e ensaiada com uma gravação.

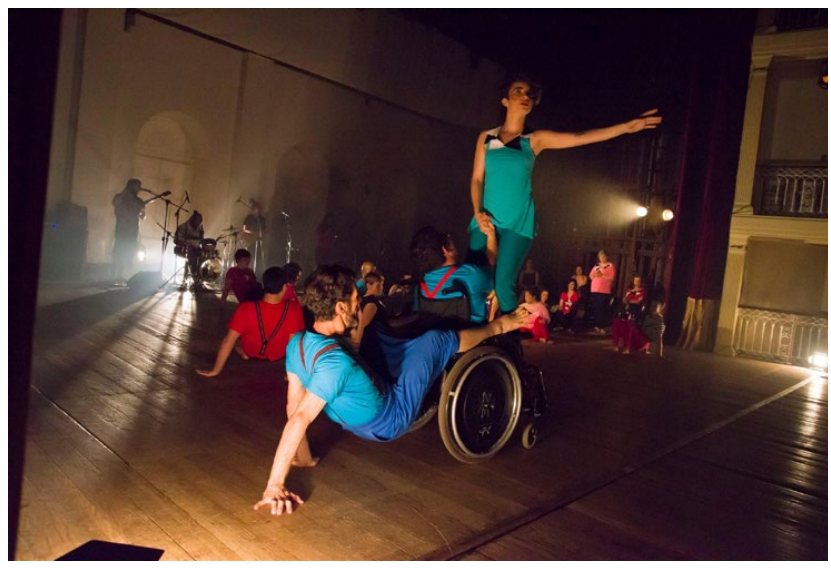

Figura 1. Entrada da coreografia Coelhinho, DCD, TSP, Porto

Alegre/RS, $2015^{20}$.

O espetáculo realizado no dia 8 de dezembro, teve uma duração de 60 minutos e contou com quatorze momentos, que foram criados por Carla Vendramin em colaboração com os dançantes do DCD, os integrantes da banda, bem como os artistas convidados. Foram feitas três composições coreográficas e dez improvisações estruturadas. As improvisações foram feitas com alguns parâmetros de movimento e definições de entrada e saída, das relações espaciais e sequência de tarefas, sendo que a movimentação era livre, a partir desses geradores de movimento. Rolf Gelewski define improvisação estruturada em diálogo com a metodologia usada, pois traz processos que investem na autonomia pessoal e consequentemente de grupo.
19. Autoria de um dos integrantes da banda, Gabriel Grillo.

20. Imagens de Jorge Diehl. 
A improvisação estruturada é um processo que visa construir, a partir de poucos elementos iniciais, uma consciência real que possa ser, para o indivíduo, apoio e fonte continuamente promotora de um trabalho de autodescoberta e autoformação (GELEWSKI, 1973, apud PASSOS, 2012, p. 84).

Nesse sentido, as estruturas servem para organizar a improvisação, delimitando um ponto de partida, de chegada, de estabilização e de circulação pelo espaço e em que momento cada uma dessas ações acontecem. Se trata de indicações que permitem que a dança flua e que os dançarinos tenham um suporte para desenvolver suas criações. O modo de trabalho do grupo DCD propõe improvisações com propostas que asseguram uma estrutura para a apropriação dos participantes, que fixam alguns parâmetros, tarefas e movimentos. Com o decorrer da atividade proposta, quando o grupo vai ficando mais seguro de suas ações, vão sendo inseridas tarefas mais arriscadas e com maior liberdade e possibilidades. De acordo com o modo de entender improvisação de Adam Benjamin, o qual é uma referência presente para o grupo:

[...] a razão pela qual improvisamos é precisamente aquela em que encontramos com o desconhecido e que nos desafia a mover e pensar em novos caminhos. É apenas a mudança inesperada dos acontecimentos e a estranha atração de circunstâncias não premeditadas, que realmente trazem a improvisação para a vida e fornecer insights sobre novas jornadas coreográficas. A improvisação ensina-nos diariamente a reajustar nossa percepção sobre ocorrências que talvez, normalmente, consideramos como erros ou distrações (2002, p. 49) ${ }^{21}$.

Segundo Benjamin, a prática da dança com grupos mistos de pessoas com e sem deficiência encontra um potencial criativo na solução de problemas, erros e tensões que podem surgir. A improvisação oferece um terreno fértil para os dançarinos desenvolvem habilidades sensiveis e autonomia.

Dar nome a cada improvisação ou às cenas no processo de criação do espetáculo serviu para facilitar o entendimento das tarefas e da estrutura. Para isso foram utilizados os nomes das músicas, apelidos dos dançantes envolvidos em cada trecho ou alguma referência da tarefa. A apresentação se constituiu das cenas: a) o vento que leva (Abertura/ Estranhos Vestíveis ( Todos); b) corredores; c) as cinco meninas; d) Carla e Gusta: Dança com a cadeira + Três duos no chão; e) solo de Mickaella (trapézio); f) Miriam / Gessi / Grillo - "Bolhas"; g) gergelim; h) Cleo / Ro / Paula; i) Paula / Carla / Margarina - redemoinhos; j) Bróder / Roberta; k) Guina / Cadeiras; 1) Dani / Julia; m) coelhinho; n) bis.

A abertura da apresentação foi criada com três momentos.
21. Tradução livre dos autores. 
Primeiramente a entrada da Banda Novo Circo Companhia de Dança entoando a música O Vento que Leva. Nesse momento, eles tocaram os primeiros acordes sem o som da bateria e dos demais instrumentos de cordas, usando apenas aqueles que não necessitavam de uso de energia mecânica. Também não foram utilizados auxílios de amplificadores e microfones.

O segundo momento foi a cerimônia de abertura em que Carla e Rogério Per Franza, integrante do DCD, apresentaram o espetáculo. Ambos estavam vestindo as peças da coleção Estranhos Vestíveis da artista gaúcha Lisi Rabello. Os objetos que os dançantes vestiam não eram meramente ilustrativos. Eles traziam um comentário sobre estranhamento, assim como o próprio nome dado pela artista ao nomear as peças criadas por ela. Carla vestia trajes nudes e uma estrutura móvel de ferro, o qual foi nominado por Lisi como Tacones Lehanos. A estrutura de cor cinza era em forma de barril com pontas protuberantes para fora e com uma parte onde saiam tentáculos da sua superfície superior. Vestindo essa estrutura, Carla alargava seu corpo, podia se esconder e aparecer novamente de dentro dele. Rogério usava uma escultura nomeada por Lisi como Paixão, feita em formato de muitas mãos que cobriam parte do seu corpo. Com cinco mãos na parte da frente e cinco mãos na parte de trás, juntamente com seus próprios braços, Rogério parecia ter doze mãos. O duo de apresentadores em Estranhos Vestíveis introduzia e convidava o público a apreciar os diversos corpos dançantes que compunham o grupo.

O terceiro e último momento que caracterizou a abertura foi quando todos os dançantes entraram em cena e se moveram livremente ao som da música O Vento que Leva. Na primeira parte os músicos entraram tocando a canção de forma mais branda e, quando os dançantes entraram em cena, a energia empregada pela banda foi outra, mais intensa, estimulando a movimentação e a relação entre todos. Esse momento evidencia uma característica que com frequência é encontrada no grupo, a celebração, a comunhão e o compartilhamento através da dança.

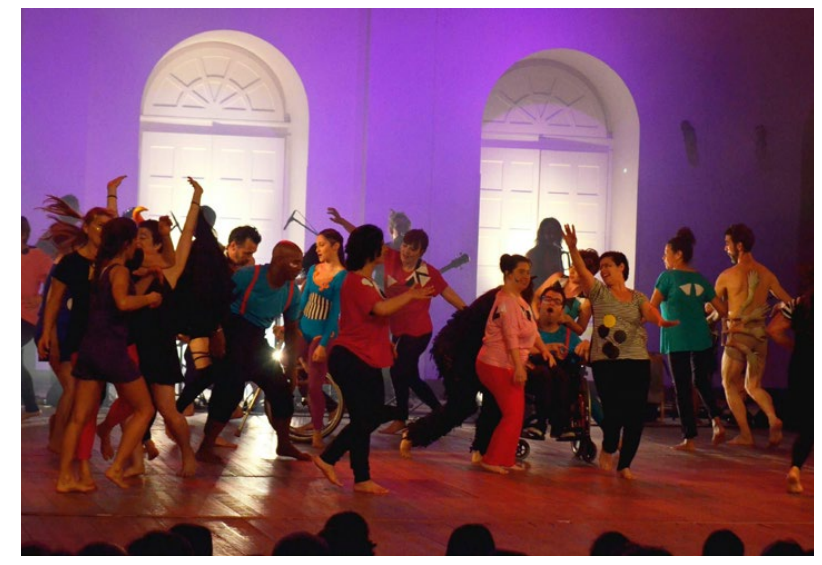

Figura 2.

Cena de $O$ vento que leva, DCD, TSP, Porto Alegre/ RS, 2015. 
Em Corredores, nove dançantes se colocavam em formato de linhas ou colunas, formando corredores e realizavam movimentos de aproximação e afastamento do público, indo para frente e para trás, se relacionando entre eles pelas laterais dos corredores imaginários. Os dançantes eram afetados pela presença do corpo um do outro, enquanto outros sete participantes cruzavam seus caminhos em trajetórias a partir de uma sequência fixa de movimentos. Nesse momento três mulheres do grupo eram seguidas por quatro dos dançarinos convidados, que se diferenciavam por seus figurinos. Thaís Petzhold estava vestida de gato com uma calça de franjas pretas. Robson Duarte se chamava Minotauro Rec-Poa, vestia bombachas, tiras cruzadas sobre o peito e uma touca com guampas, a qual uma delas estava quebrada. Ana Medeiros vestia um colante e asas verdes e Marco Filippin um corpete vermelho e cinta-liga. O figurino do grupo tinha um mote circense, com cores vibrantes, listras e bolas. O figurino dos dançarinos convidados também pontuava a diversidade, dando vasão a diversidade de seres, que fez parte da proposta desse trabalho. O figurino, assinado por Vanessa Berg do Estúdio Hybrido, estava afinado com a proposta, inclusive na vestimenta escolhida por ela para a banda.

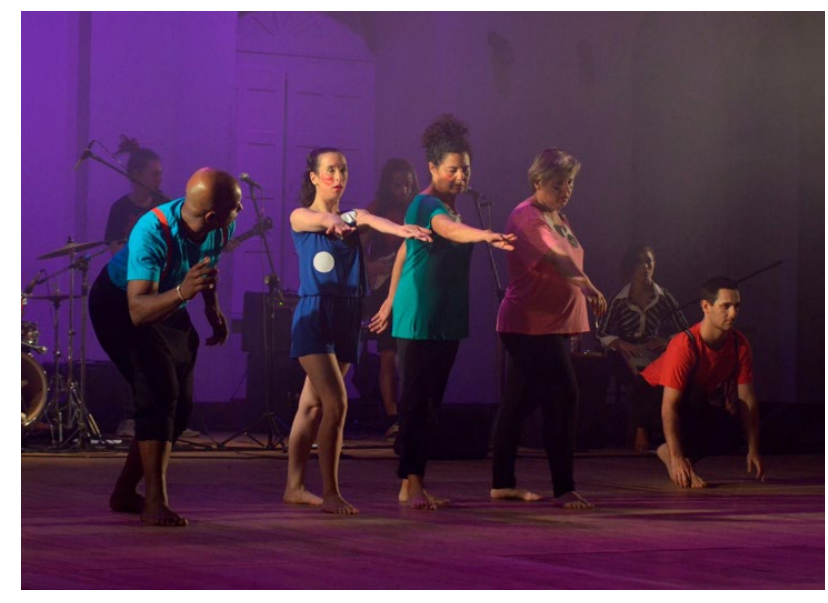

Figura 3.

Cena de Corredores, DCD, TSP, Porto Alegre-RS, 2015.

Na improvisação As Cinco Meninas, as dançantes diziam seus nomes e reproduziam um movimento a cada vez que se moviam. Elas iam compondo imagens com a forma como se posicionavam. Essa estrutura foi continuada no decorrer da coreografia, sem dizer o nome, mas com uma movimentação de ação e resposta. O desenvolvimento dessa improvisação se deu a partir de como foi gerado seu início, através de uma tarefa simples, que progrediu para uma maior complexidade em seguida, fazendo um cânion com movimentos sequenciados. Para tanto, cada dançante percebia como a outra reagia para poder assumir o seu movimento. Essa escuta era igualmente presente tanto para a dançante que possui déficit 
de memória e as que possuem deficiência intelectual, quanto para aquelas que não possuem deficiência.

O duo entre Carla e Gusta deu início a uma cena que foi encerrada no chão e que é dividida em três partes. Primeiro, Carla e Gusta, estabelecem uma relação de movimento que se dá através dos sons produzidos pelos dois dançantes. A dançarina convidada Thais Petzhold, que ficava na parte lateral do palco, entrava reproduzindo sons de assovio com a boca. Por meio dos sons com ela, os outros dois dançantes começavam um jogo de avançar e recolher, aparecer e esconder, para então Gusta ser levado para o chão com o apoio de Carla. Se precisou coordenar alguns detalhes funcionais para que eles também se tornassem cênicos, como tirar os óculos do Gusta e colocá-lo depois na bolsa atrás das costas da cadeira de rodas; colocar os freios e abri-los novamente no momento certo para a movimentação da cadeira; e para direcionar o Gusta até o chão. Assim como encontrado nessa cena, a resolução de forma cênica de movimentos que seriam apenas funcionais precisam ser atendidos para que dançantes que possuem deficiência estejam completamente envolvidos na proposta artística.

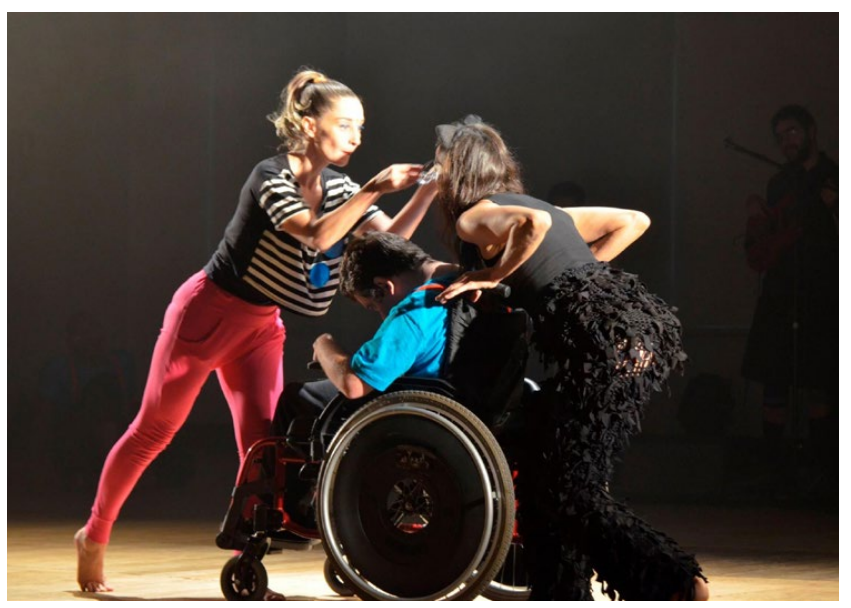

Figura 4.

Carla, Thais e Gusta, DCD, TSP, Porto Alegre/ RS, 2015.

Em seguida, a cadeira de rodas se transforma em uma parceira entre o duo de Carla e Rogério, como um elemento cênico. O trio Cadeira-Carla-Rogério desloca-se pelo espaço do palco. Thaís e Gusta se movimentavam no chão, em uma trajetória em que, mais adiante, encontraram novamente Carla. Aos poucos, outros dançantes foram entrando, caminhando na posição que eles chamavam de aranha, isto é, em decúbito dorsal e com as mãos e pés apoiados no chão. Além de Carla e Gusta, quem entrava compunha uma outra dupla. Quando se formaram três duplas reunidas em posição fetal, iniciou uma coreografia com base no contato, direcionada a partir dos sons que os dançantes faziam para indicar as mudanças de 
movimento. No final desta parte, Thaís dançava com a cadeira levando-a para a lateral do palco.

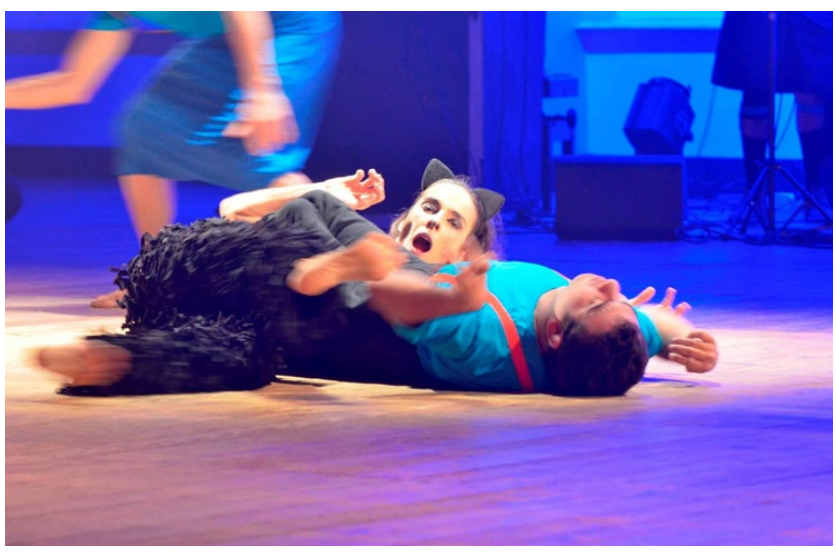

Figura 5.

Thais e Gusta, DCD, TSP, Porto Alegre/RS, 2015.

No terceiro momento desta cena, os três casais deitados em posição fetal viravam de um lado para o outro e em direções opostas, se encontrando frente a frente em alguns momentos. Essa coreografia foi criada a partir de movimentos do Gusta, encontrados na pesquisa corporal entre ele e Carla. A relação de peso e contrapeso fazia com que um dos dançantes impulsionasse o outro deitado para cima. As mudanças de posição eram direcionadas através do som também a partir do Gusta, pois para ele, fazer sons surgiu de forma a constituir seu modo de dançar. A cena terminava com todos os dançantes saindo para as laterais do palco. Em duplas, um dançante carregava o outro na posição de aranha. Essa foi outra criação artística para solucionar o modo em que o Gusta voltou para a cadeira de rodas, desta vez, sem o público ver e sem que isso participasse da cena.

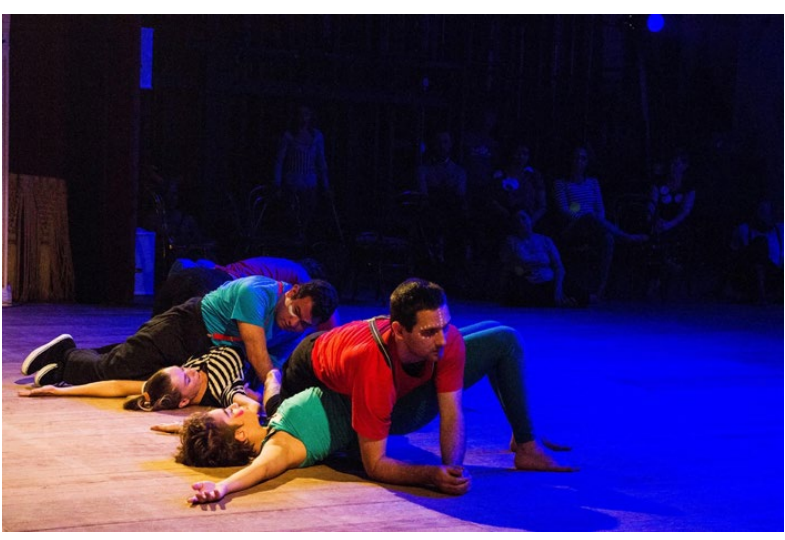

Figura 6.

Três duos no chão, DCD, TSP, Porto Alegre/RS, 2015.

A dançarina potiguar Mickaella Dantas, uma das convidadas, é integrante do grupo Dançando com a Diferença22, dirigido por Henrique Amoedo. Ela atua profissionalmente também em outras companhias de dança e atualmente pratica artes circenses em Portugal, onde reside. Na apresentação no

22

Grupo de dança contemporânea da Ilha da Madeira em Portugal, criado a partir de um projeto realizado entre setembro de 2001 a junho de 2007 e que tem pessoas com e sem deficiência no seu elenco, com um repertório de coreografias criadas por convidados. Disponível em http:// www.aaaidd.com/index. php?option=com_content\&task $=$ view\&id $=5 \&$ Itemid $=8$. Acesso em: 4 maio 2016. 
TSP, Mickaella apresentou um solo que iniciava com trajetórias pelo palco, usando muletas para se locomover, e depois dançava em um trapézio pendurado no lado direito. As muletas ampliavam a extensão de seus braços, Mickaella se apoiava sobre elas, ia para o chão e voltava dele até ficar em pé e alcançar o trapézio, quando começou seu solo aéreo. Nesse momento não houve interação por parte dos integrantes do $\mathrm{DCD}$, porém, eles estavam conscientes da sua presença em cena enquanto estavam nas laterais do palco. O palco era aberto, sem pernas e ciclorama. Nas laterais haviam cadeiras empilhadas e outras em que os dançantes se sentavam. Em nenhum momento eles saíram do palco. Sempre que não estavam dançando, eles ainda estavam visíveis nas laterais do palco, e precisavam manter a percepção da sua presença em cena. Isso se dava pois o processo do grupo possibilitava que os dançantes se percebessem como corpo cotidiano, ativo e vibrante, pronto a dançar, e sensível ao que estivesse acontecendo em cena.

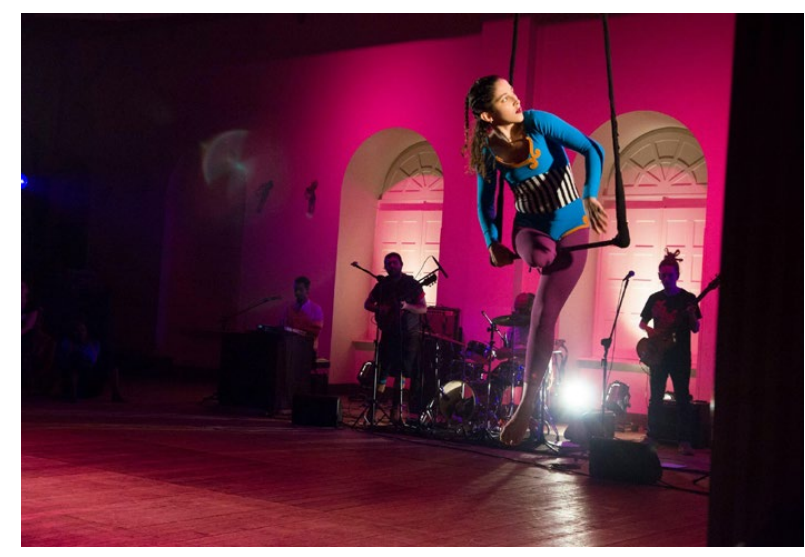

Figura 7 .

Cena do trapézio com Mickaella, DCD, TSP, Porto Alegre/RS, 2015.

Na cena seguinte, Bolhas, Gabriel Grillo, um dos integrantes da banda, manipulava uma esfera de cristal enquanto as participantes do DCD, Miriam e Gessi dançavam. O músico, agora na função de artista circense, manipulava o cristal transferindo-o de um braço para o outro por meio do equilíbrio e rolamento da bola sobre seu corpo. As duas dançantes também faziam um jogo de equilíbrio e transferência de peso. Havia uma composição de distâncias, em que a dupla e o músico se afastavam e se aproximavam. As bolhas de sabão que os integrantes da banda sopravam ajudava a trazer uma atmosfera nostálgica para a cena. As criações sobre a participação dos integrantes da banda foram propostas por eles mesmos, juntamente com a coordenadora do grupo. Elas surgiram nas conversas em que tinham durante ensaios da banda e nos momentos de ensaio com o DCD. Na primeira apresentação, no teatro do Centro Cultural Santa Casa, dois entre os seis integrantes da banda, fizeram entradas com o grupo, pois ainda muitas das cenas apresentadas posteriormente no TSP não tinham sido criadas. 
Em Gergelim, a cena envolveu todos os artistas do espetáculo, inclusive os músicos. Gergelim surgiu de uma gravação demo da banda, onde se ouvia a interação deles com o público cantando. Os dançantes entravam de lados diferentes do palco, divididos em três grupos, cada grupo cantando uma dessas três frases: pão bom, pão bom; pão com gergelim e um miolo bem gostoso. Eles faziam percussão corporal e iam se juntando no centro do palco, aumentando a intensidade do canto e depois diminuindo até parar. O grupo então se dissipava e a artista convidada, Vera Carvalho, entrava para fazer um número com bambolê.

Em seguida, as participantes do DCD, Cleonice e Rosane dançavam enquanto Paula, uma integrante da banda, tocava castanholas. Paula dançava com suas castanholas se movendo em torno da dupla e compondo com elas. Cleo e Ro compartilhavam um leque e a movimentação da sua improvisação acontecia a partir da tarefa guiar e seguir. O leque servia como objeto cênico que induzia a movimentação.

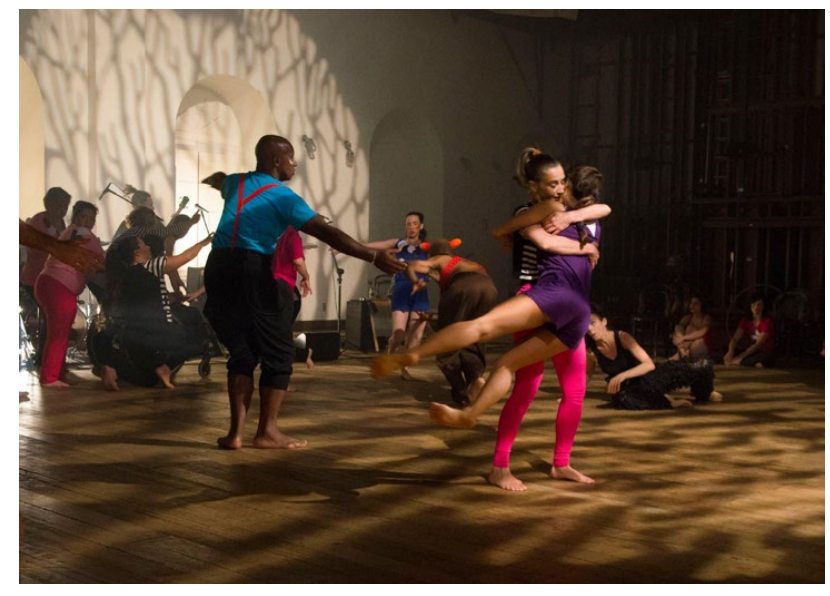

Figura 8.

Cena Redemoinhos, DCD, TSP, Porto Alegre/RS, 2015.

A próxima cena, Redemoinhos, era iniciada por Carla, Paula e o músico Margarina, que fazia malabares com claves. Carla e Paula entravam no palco com a intenção de girar o espaço e logo elas mesmas é que começavam a girar, juntamente com Margarina, criando os redemoinhos. Depois entravam três dos dançarinos convidados, seguidos de alguns dos integrantes do grupo DCD. Eles faziam um grande redemoinho de pessoas que giravam, que às vezes se encontravam em um abraço e às vezes desciam e voltavam em espiral até o chão, em diferentes velocidades. Essa cena terminava quando o grupo começava a rolar pelo chão dando risadas. Esse momento foi inspirado por Cleonice, que tinha uma gargalhada muito característica. Em uma das aulas em que estávamos fazendo um trabalho no chão, Cleonice descobriu o rolamento e se divertiu muito fazendo essa movimentação continuamente dando altas risadas. Novamente, a criação feita foi a partir de movimentos particulares de um dos dançantes. 
Aos poucos a cena foi se transformando e se formou um grande grupo na parte inferior direita do palco, da perspectiva de quem assiste. Essa era a preparação para a cena seguinte com o participante do DCD, Broder, e a artista convidada, Roberta. O grupo aglomerado ao lado direito, se movia lentamente. O mote de movimento deles era imaginar a sua frente que havia um sol brilhante e então mover partes do seu corpo para serem iluminadas por ele. A escuta, abordada dentro do processo do grupo, permitiu que eles conseguissem compor com seus movimentos um em relação ao outro. Enquanto isso, à esquerda do palco, Broder e Roberta dançavam, fazendo uma improvisação que tinha um começo e um fim definido, mas era livre no meio. O grupo, embora estivesse fixo em um lugar, fazia uma exploração do seu pequeno espaço, enquanto a dupla investigava as inúmeras possibilidades do espaço maior, criando duas imagens distintas, porém complementares.

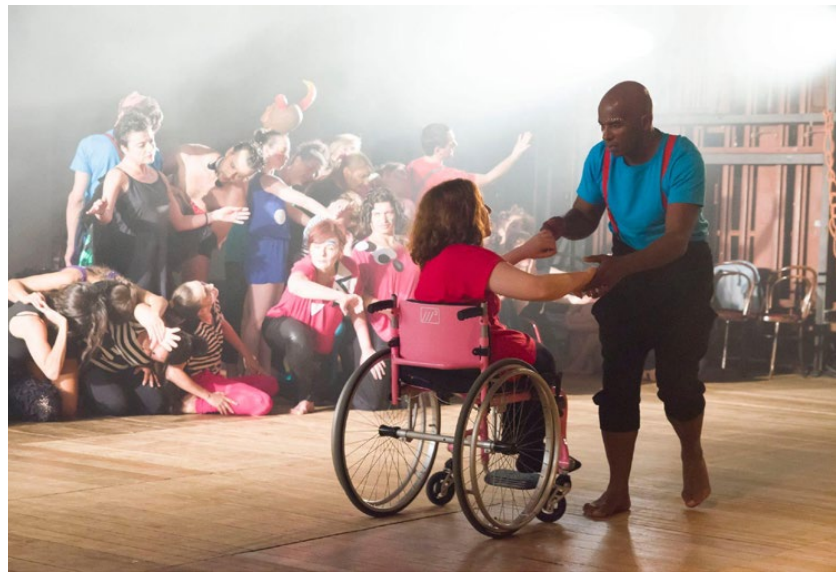

Figura 9. Duo de Bróder e Roberta com grupo ao fundo DCD, TSP, Porto Alegre/RS, 2015.

Paulatinamente, essa massa de bailarinos ao fundo foi se dissolvendo lentamente e o que era uma relação de olhar focada naquela direção tornou-se uma horizontal. Os dançantes se espalharam levando as cadeiras da lateral para fazer uma linha, criando uma espécie de muralha ao fundo do palco e à frente da banda para a formação da cena Cadeiras. Eles ficavam ao fundo como uma paisagem, enquanto Guina, um dos músicos, sentava-se a frente do palco manipulando uma clave. Os dançantes se movimentavam lentamente com contato entre as superfícies da cadeira e de seus corpos que, com a iluminação contra suas costas, ficavam visíveis apenas pela silhueta. A muralha formada se desfazia e os dançantes iam para as laterais do palco, abrindo espaço para a próxima cena, o duo de Dani e Júlia. Para fazer essa coreografia, foram feitos encontros em momentos fora dos dias estipulados para os ensaios do grupo. Embora houvesse inúmeras mudanças no meio do processo, criou-se uma trajetória em que, inicialmente, as dançantes se encontravam e se desencontravam, entravam e saiam da cines- 
fera uma da outra, permitiam dar e receber apoio e seguiam uma a outra.

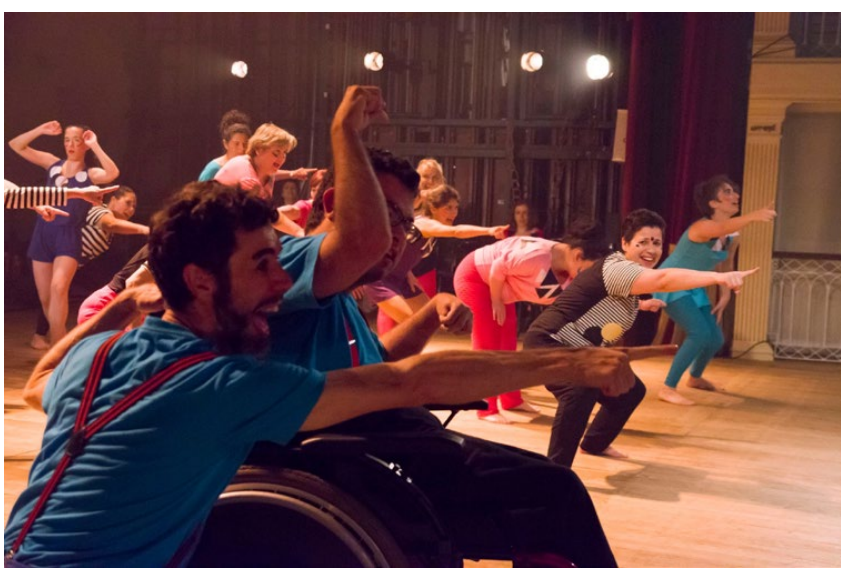

Figura 10.

Cena de Coelhinho, DCD, TSP, Porto Alegre/RS, 2015

A cena final era marcada pela música chamada Coelhinho. Essa foi a única composição coreográfica em que o grupo todo dançou, exceto os dançarinos convidados. Na parte do refrão, em que eles cantam E agora quem vai tirar/O coelho da cartola, tinha uma sequência de gestos que sublinhavam a letra, que foi criação de um dos integrantes do grupo, o Margarina. O restante da movimentação foi uma criação de Carla, usando gritos e sons relacionados aos movimentos, demarcando partes da música. A última cena terminava de forma vibrante em uma atmosfera circense, tema de uma das músicas. O momento do Bis foi feito em seguida e veio da ideia da coreógrafa e dos músicos da banda de que esse espetáculo não era uma apresentação de dança simplesmente, mas um grande show ou um híbrido de ambos. Por isso, o Bis, presente em shows musicais e caracterizado pelo momento final da apresentação, em que o músico vai embora e a plateia solicita o seu retorno, tornou-se uma ideia divertidamente possível para o espetáculo. Porém, ao invés de esperar a aclamação do Bis, o público foi convidado a subir no palco para dançar com o grupo e os músicos.

Dentro desse processo, é importante levar em consideração os desafios de realizar um espetáculo em um teatro com grandes proporções, diferente da habitual sala em que foram realizados os ensaios. A apresentação realizada no Teatro do Centro Cultural Santa Casa foi uma excelente experiência, que serviu para o grupo se sentir mais apropriado de seu trabalho para apresentar em um teatro maior. Com a abordagem da prática em dança feita, foi possível que o grupo se adaptasse sem muita dificuldade ao espaço do Theatro São Pedro. A apresentação especificamente nesse teatro foi importante por ser um centro cultural com mais de um século de história, onde acontecem inúmeras apresentações de óperas, de artistas e compa- 
nhias do mundo todo, validadas pela sociedade como arte. O glamour trazido pelo Theatro São Pedro foi um fator importante nesse processo, por ocupar um espaço elitizado e dar visibilidade e reconhecimento ao trabalho do grupo. Teixeira nos chama a atenção para questões sociais referentes a dançarinos com deficiência em cena:

\begin{abstract}
Quando falamos em cena envolvendo bailarinos com algum tipo de deficiência, caímos em território ainda por ser desvendado, cujas interpretações repousam em avaliações sistematizadas e em procedimentos laboratoriais de verificação-aplicação de métodos, bem como das possibilidades criativas dos corpos. Sendo assim, parece-me que caímos em um discurso no qual a subestimação das capacidades do corpo considerado diferente, justifica a aplicação do modelo de teste, da verificação, que instrumentaliza o corpo não-deficiente para a interpretação pró-deficiente. A superexposição de suas patologias ou de suas capacidades físicas como atos heroicos, em lugar de seus processos de autoria e criação artística, reflete o contexto atual desses artistas. (2011, p. 103)
\end{abstract}

Inevitavelmente, existem paradigmas que permeiam o trabalho de artistas e grupos que envolvem pessoas com deficiência. Para um grupo que evidencia seu trabalho como artístico e não terapêutico, e em que os lugares de gueto são mais comuns do que lugares de participação social e de glamour, ter dançado no Theatro São Pedro foi uma estratégia de visibilidade, resistência e apreciação como trabalho artístico de qualidade, dentro da área da dança na comunidade.

A visibilidade gerada pelas apresentações, atraiu a atenção da mídia que, durante o processo de criação do espetáculo, produziu uma matéria que foi ao ar no dia 21 de novembro de 2015 no Jornal do Almoço ${ }^{23}$, telejornal gaúcho, transmitido pela RBSTV, filiada da Rede Globo no Rio Grande do Sul, com consideráveis índices de audiência no horário do meio-dia. A jornalista responsável pela realização da matéria foi Isabel Ferrari, que entrevistou integrantes e pais sobre a sua relação com a dança, bem como a visão sobre o assunto frente aos paradigmas em relação à dança e deficiência. Foram feitos registros de alguns ensaios. Posteriormente, a equipe de gravação também registrou a apresentação no Theatro São Pedro. Contudo, essa apresentação não foi ao ar por questões editoriais, segundo a própria jornalista. A reportagem contribuiu para difundir o trabalho do grupo Diversos Corpos Dançantes. Com um foco sobre as pessoas com deficiência, o título da reportagem trazia a seguinte informação: Aula de dança transforma a vida de pessoas com deficiência em Porto Alegre.

O processo criativo do grupo proporcionou uma experiência substancial e enriquecedora, tanto para os integrantes
23

Disponível em http:// g1.globo.com/rs/rio-grande-do-sul/jornal-do-almoco/ videos/t/porto-alegre/v/ aula-de-danca-transforma-vida-de-pessoas-com-deficiencia-em-porto-alegre/4624571/ Acesso em 7 de Setembro de 2016 
do Diversos Corpos Dançantes, quanto para os dançarinos convidados, a equipe de apoio e a banda Novo Circo Companhia de Dança. O processo de construção do grupo, perpassando duas apresentações e a relação com os artistas que foram sendo incluídos criou um sentido de coletividade, onde singularidades eram trazidas a luz. O processo enfatiza um trabalho cuja relação singularidade/coletividade se dá no reconhecimento do grupo como sendo de habilidades mistas, no conjunto da sinergia da participação de todos seus integrantes, sendo do grupo DCD ou convidado externo. A construção coletiva do trabalho, envolvendo as potencialidades dos participantes trouxe a perspectiva de uma dança compartilhada, a dança na comunidade.

\section{Considerações Finais}

Tendo em vista que na dança na comunidade pode-se trabalhar com uma variedade de pessoas, a improvisação vem a ser um modo de estudo/criação/atuação em dança compatível para potencializar esses corpos. Busca-se estar atento a singularidade dos envolvidos, procurando desenvolver processos coletivos para trabalhar nas aulas e ver a efetividades dessas proposições em cena, o que pode ser visto através do espetáculo tratado neste texto. 


\section{REFERÊNCIAS}

BENJAMIN, Adam. Making an Entrance: Theory and practice for disabled and non-disabled dancers. Routledge, London and New York. 2002. 255 p. ISBN 041-52-2514-43.

COHEN, Bonnie Bainbridge. Sensing, Feeling and Action: The Experiential Anatomy of Body-Mind Centering ${ }^{\circledR}$. 3. ed. Northampton: Contact, 2012. 219 p. ISBN 978-09-376-4503-1.

CORPALAVRA. Fotos da oficina de dança. Disponível em: http:// corpalavra.blogspot.com.br/2011/og/fotos-da-oficina-dedanca. html Acesso em 7/og/2016.

FERRAZ, Wagner. Corpo a Dançar: Entre educação e criação de corpos. 2014. Dissertação (Mestrado em Educação) - Faculdade de Educação, Universidade Federal do Rio Grande do Sul, Porto Alegre, 2014.

FERRAZ, Wagner; BELLO, Samuel Edmundo Lopes. Rastros Genealógicos de Dança: para pensar um corpo dançante. Informe C3, v. 1, n. 16, 2014. Disponível em: https://pt.scribd.com/ doc/275771451/Rastros-Genealogicos-de-Danca-Para-pensa-umcorpo-dancante-Ferraz-Wagner . Acesso em: o7 set. 2016.

G1.GLOBO.COM. Mostra brasileira de dança abre inscrição para oficinas no Recife. Disponível em: http://g1.globo.com/pernambuco/noticia/2012/o6/mostra-brasileira-de-danca-abre-inscricao-para-oficinas-no-recife.html Acesso em 7 de Setembro de 2016.

IDANÇA.NET. O nome da coisa. Disponível em: http://idanca. net/o-nome-da-coisa/ Acesso em 7 de Setembro de 2016.

INCLUSIVE.ORG.BR. Dança acessível. Disponível em: http:// www.inclusive.org.br/arquivos/18073 Acesso em 7 de Setembro de 2016a.

INCLUSIVE.ORG.BR. Perspectivas: instalações coreográficas. Disponível em: http://www.inclusive.org.br/arquivos/20425 Acesso em 7 de Setembro de 2016b.

KUPPERS, Petra. Community Performance: an introduction. Routledge, London and New York, 2007. 252 p. ISBN 978-04-1539-229-7.

KUPPERS, Petra.TheCommunity PerformanceReader. Routledge, London and New York, 2007. 283 p. ISBN 978-04-1539-231-0.

PASSOS, Juliana Cunha. Rolf Gelewski e as inter-relações entre forma, espaço e tempo: uma proposta pedagógica de improvisação para processos criativos em dança. 2012. Dissertação (Mestrado em Artes da Cena) - Instituto de Artes, Universidade Estadual de Campinas, Campinas, 2012. 
SECRETARIA DA CULTURA DO RIO GRANDE DO SUL. Inscrições abertas para oficina gratuita de dança na CCMQ. Disponível em: http://www.cultura.rs.gov.br/v2/2012/o3/ inscricoes-abertas-para-oficina-gratuita-de-danca-na-ccmq/ Acesso em 7 de Setembro de 2016a.

SECRETARIA DA CULTURA DO RIO GRANDE DO SUL. Batepapo e oficina de dança contemporânea na CCMQ. Disponível em: http://www.cultura.rs.gov.br/v2/2012/10/bate-papoe-oficina-de-danca-contemporanea-na-ccmq/ Acesso em 7 de Setembro de $2016 \mathrm{~b}$.

SWAIN, J.; FRENCH, S; CAMERON, C. Controversial issues in a disabling society. Berkshire: Open University Press, 2005. 216 p. ISBN 978-03-3520-904-0.

TEIXEIRA, Ana Carolina Bezerra. Deficiência em Cena. João Pessoa: Editora Ideia, 2011. 189 p. ISBN 978-85-7539-660-5.

TEIXEIRA, Ana Carolina Bezerra. Impossible Dances: Staging disability in Brazil. Choreographic Practices, v. 06, n. 01, 2015. Disponível em <https:/docs.com/carolina-teixei/8597/ impossible-dances-staging-disability-in-brazil > Acesso em: 7 set. 2016.

VARREGOSO, Isabel et al. Danças - Vivências contemporâneas na comunidade. Revista da Sociedade Cientifica de Pedagogia do Desporto, Rio Maior, Portugal, v. 01, n. 05, 2014. Disponível em <http://repositorio.ipsantarem.pt/bitstream/ 10400.15/1149/1/Artigo_Dan\%C3\%AJa-Viv\%C3\%AAnciasContempor\%C3\%A2neas.pdf> . Acesso em: 7 set. 2016.

VENDRAMIN, Carla. Diversas danças - diversos corpos: discursos e prática da dança no singular e no plural. Revista DO CORPO: Ciências e Artes, Caxias do Sul, v. 1. n.3, 2013. Disponível em <http://www.ucs.br/etc/revistas/index.php/docorpo/article/ view/2904/1694>. Acesso em: 7 set. 2016. 